\title{
Normative Values of Cardio-Respiratory Endurance in Adults in Benin
}

\section{H. Etienne Alagnide*, D. Didier Niama Natta, Emmanuel Sogbossi, Wilfried Dahoueto, Eric Dossa, M. Antonin Agbogbo, G. Toussaint Kpadonou}

University Clinic of Physical Medicine and Rehabilitation, CNHU-HKM, Cotonou, Benin

Email: *ealagnide@yahoo.fr

How to cite this paper: Alagnide, H.E., Niama Natta, D.D., Sogbossi, E., Dahoueto, W., Dossa, E., Agbogbo, M.A. and Kpadonou, G.T. (2021) Normative Values of Cardio-Respiratory Endurance in Adults in Benin. Open Journal of Therapy and Rehabilitation, 9, 143-153.

https://doi.org/10.4236/ojtr.2021.94012

Received: August 20, 2021

Accepted: November 23, 2021

Published: November 26, 2021

Copyright $\odot 2021$ by author(s) and Scientific Research Publishing Inc. This work is licensed under the Creative Commons Attribution International License (CC BY 4.0).

http://creativecommons.org/licenses/by/4.0/

\begin{abstract}
Cardiorespiratory endurance is a determining factor in the assessment of the state of health of a person. Objective: To determine the reference values for cardiorespiratory endurance in Beninese adults. Methods: Prospective transversal study, with a descriptive and analytical aim. It was carried out on healthy adult subjects (18 to 50 years old), of Cotonou and Abomey cities, from October 2017 to May 2018, without clinically identifiable orthopedic, cardiorespiratory, osteoarticular or neuromotor impairment. These subjects performed three different cardio-respiratory endurance tests: The six-minute walk test (WT6), cycloergometer test (CT) and the step test (ST). Data processing and analysis were done using SPSS version 22 software. A linear regression model was used to establish the prediction equation of maximal oxygen uptake $\left(\mathrm{VO}_{2}\right.$ $\max$ ) with the WT6 data. The significance level chosen was 5\%. Results: Subjects average age was $30.0 \pm 9.8$ years. It was especially men $(54.20 \%)$, students $(42.13 \%)$, with a normal corpulence (69.91\%). At WT6, they walked $365 \mathrm{~m}$ to $798 \mathrm{~m}(557.1 \pm 93.6 \mathrm{~m})$ with extreme heart rates (EHR) of 67 to 189 $(136.7 \pm 19.0)$ beats per minute. At ST, the extreme powers developed were 2.7 watts $/ \mathrm{kg}$ and 11.8 watts $/ \mathrm{kg}(6.4 \pm 1.8$ watts $/ \mathrm{kg})$, with EHR of 99 to 204 $(168.4 \pm 15.4)$ beats per minute. The predictor equation of $\mathrm{VO}_{2}$ max by WT6 was function of the subject's weight, age and sex $(R=0.73)$. ConclusionDiscussion: These normative values of cardio-respiratory endurance of Beninese subjects seem to be specific to them. An extension of the present study to a larger sample nevertheless seems desirable.
\end{abstract}

\section{Keywords}

Cardio-Respiratory Endurance, 6-Minute Walk Test, Step Test, $\mathrm{VO}_{2} \mathrm{Max}$, Benin 


\section{Introduction}

Cardiorespiratory endurance (RCT) is the ability of the heart, lungs, and circulatory system to efficiently deliver oxygen and nutrients to muscle mass required during prolonged physical exertion [1]. This is a very important piece of information about the state of health of a person [2]-[13]. Its assessment is therefore decisive during the examination of any patient, in order to adapt the level of activity during patient rehabilitation sessions. $\mathrm{VO}_{2} \max$ is the parameter of choice for this assessment [14]. Its estimate is made, based on various tests including the 6-minute walk test [15]. So it requires reference to normative values [16] [17]. The latter is not currently being available in Benin. It is for this purpose that we initiated this study, which objective is to determine reference values of cardiorespiratory endurance in Beninese adults.

\section{Methods and Materials}

\subsection{Type and Period of Study}

This is a cross-sectional prospective study with a descriptive and analytical aim. It was done from October 06, 2017 to May 25, 2018, i.e. over a period of eight (08) months.

\subsection{Study Population and Sampling}

Our study population took into account healthy adult subjects from Cotonou and Abomey cities. A healthy subject was defined as any person having no apparent orthopedic impairment objectified on examination and having no impairment of cardiorespiratory, osteoarticular, and neuromotor function. The sampling was carried out taking into account healthy adult subjects, aged 18 to 50 years, living in Cotonou or Abomey (or in one of their neighboring municipalities) and having consented to participate to the study. Pregnant women (female) were excluded.

The list of subjects was made by raising awareness in public places (churches, market, sports ground, schools, workshops, etc.). An appointment was made with the consenting subjects, either at the University Clinic of Physical Medicine and Rehabilitation of the National Hospital and University Center (CNHU-HKM) of Cotonou or the functional rehabilitation service of the Departmental Hospital of Abomey, to carry out their cardio-respiratory endurance tests.

\subsection{Cardio-Respiratory Endurance Tests Done}

For the evaluation of cardio-respiratory endurance, subjects had in two separate sessions of at least one week, three different tests: The six-minute walk test and the cycloergometer test at the first session and the step test during the second session.

- For the six-minute walk test (6 MWT), subjects did not perform vigorous exercise within two hours of testing. They seated and were at complete rest for 
ten minutes before the 6 MWT. They wore sportswear to be comfortable during the exercise. The test was done in a flat linear corridor, marked every 1 meter over a distance of 20 meters with a stud placed at each end. Instructions given to the subjects were: "The objective of this test is to walk as far as possible in six minutes. You will go back and forth by going around the studs and keeping a straight trajectory". Encouragement given was standardized, every minute. Fifteen (15) seconds before the end of the test, subject was notified that the test was about to be completed.

- Cycloergometer test was performed after a minimum of thirty to forty-five minutes of rest after the six-minute walk test, after that the heart rate had returned to its resting value or very close to it and the subject felt ready to start. Therefore, we comfortably install subject on the bike (adjusting the height of the seat so as to avoid a flexion of more than $90^{\circ}$ of the knee during pedaling). Subject is pedaling at free pace for three minutes as a warm-up. The test began really when the bike power is reached to 50 watts, that was increased by 15 watts every minute. Subject was allowed to pedal upright when the working power became greater. Instructions given to the subject were: "Pedal at a speed between 60 and 70 revolutions/minute; do not speak during the test; pedal as long as possible". Standard encouragement was given during the test.

- For the step test, subject was first installed in a seated position on a chair so as to be put to rest for 2 minutes. After that, the resting heart rate $\left(\mathrm{HR}_{0}\right)$ was recorded and noted (step 0). Then, the subject started the test with the first board $0.1 \mathrm{~m}$ high corresponding to the first level. For 2 minutes he went up and down the board at a constant speed of 84 steps/min (step 1). At the end of this step, the heart rate $\left(\mathrm{HR}_{1}\right)$ was also recorded. The subject rested for 2 minutes, to repeat the same test, at the same pace with a board $0.2 \mathrm{~m}$ high, for 2 minutes after which the heart rate (HR2) was recorded. The same scenario was continued with boards of increasingly higher heights (incrementing 0.1 meter per step), until the subject was unable to follow the rhythm imposed by the metronome to ascend and descend.

\subsection{Parameters Collected}

On the 6-minute walk test, the total distance traveled and the heart rate immediately when stopped were recorded using the heart rate monitor worn by the subject. The maximum oxygen consumption $\left(\mathrm{VO}_{2} \mathrm{max}\right)$ was calculated, from the data of the cycloergometer test, according to the gender-specific formulas established by Thomas W. Storer:

$$
\begin{gathered}
\mathrm{VO}_{2} \max (\text { male })=10.51(\mathrm{w})+6.35(\mathrm{~kg})-10.49(\text { age })+519.3 \mathrm{ml} \cdot \mathrm{min}^{-1}, \\
\mathrm{VO}_{2} \max (\text { female })=9.39(\mathrm{w})+7.7(\mathrm{~kg})-5.88(\text { age })+136.7 \mathrm{ml} \cdot \mathrm{min}^{-1} .
\end{gathered}
$$

Relative $\mathrm{VO}_{2} \max (\mathrm{ml} / \mathrm{kg} / \mathrm{min})$ was obtained by dividing these absolute values by body weight. Also, as soon as the cycloergometer test was stopped, the heart rate (HR) was taken on the heart rate monitor by the subject. During the step test, the developed power (watts) was calculated according to the formula used 
by Nielens $\mathrm{H}$. and Plaghki L: Power $=$ weight $($ in $\mathrm{kg}) \times$ acceleration due to gravity $\left(9.8 \mathrm{~m} / \mathrm{S}^{2}\right) \times$ climb frequency $/$ second $(84$ steps/minute $) \times$ height of the last plank with which the two minutes of ascent/descent were completed. Power relative to body weight was the ratio of absolute power to subject weight.

\subsection{Statistical Analysis and Data Processing}

Encoding and processing of data were done in Microsoft office Excel version 2007 and SPSS software version 22, respectively. A descriptive analysis of the study variables was done. A correlation between $\mathrm{VO}_{2}$ max and the distance covered on the six-minute walk test was sought. A linear regression model was used to establish the predictive equation for $\mathrm{VO}_{2}$ max with the data from the sixminute walk test. The significance level chosen was $5 \%$.

\section{Results}

\subsection{Characteristics of the Study Population}

The extreme ages were 18 and 50 with a median of 28 . The mean age was $30.0 \pm$ 9.8 years. Subjects were especially men $(54.20 \%)$, students $(42.13 \%)$, with a normal corpulence (69.91\%). According to their allegations, $23.61 \%$ of them consume alcohol occasionally and $21.30 \%$ have a fairly regular practice of sport. Table 1 shows other characteristics of the study population and Figure 1 shows data on the lifestyle of study subjects.

Table 1. Distribution of study subjects, according to their socio-demographic characteristics.

\begin{tabular}{cccc}
\hline \multirow{2}{*}{ Gender } & & Number & Percentage (\%) \\
& Male & 117 & 54.20 \\
& Female & 99 & 45.80 \\
\hline \multirow{2}{*}{ Professional status } & Student & 91 & 42.13 \\
& Artisan & 43 & 19.91 \\
& Civil servant & 24 & 11.11 \\
& Others & 58 & 26.85 \\
Marital status & Single & 109 & 50.46 \\
& Married & 104 & 48.15 \\
& Widower & 3 & 1.39 \\
\hline \multirow{2}{*}{ Level of study } & University & 84 & 38.89 \\
& Secondary & 53 & 24.54 \\
& Primary & 52 & 24.07 \\
& Unschooled & 27 & 12.50 \\
\hline \multirow{2}{*}{ Corpulence } & Thinness & 36 & 16.67 \\
& Normal & 151 & 69.91 \\
& Obesity & 29 & 13.42 \\
\hline & & &
\end{tabular}




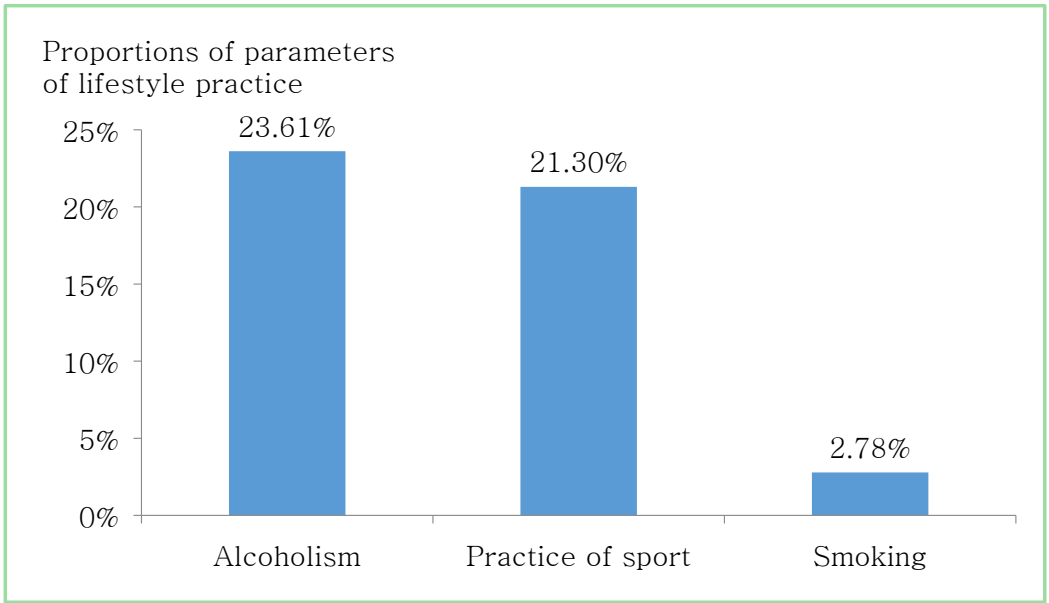

Figure 1. Distribution of subjects according to their lifestyle practices.

\subsection{Cardio-Respiratory Endurance Performance}

\subsubsection{Six-Minute Walk Test Performance}

On the 6-minute walk test, distances covered by subjects ranged from $365 \mathrm{~m}$ to $798 \mathrm{~m}$ with an average of $557.1 \pm 93.6 \mathrm{~m}$. The extreme heart rates were 67 and 189 beats per minute. The average HR was $136.7 \pm 19.0$ beats per minute. Table 2 shows the percentiles of the subjects' performance on the 6-minute walk test, for distance traveled and heart rate, by sex and age groups.

\subsubsection{Step Test Performance}

During the step test, the extreme powers developed by the subjects were 2.7 watts $/ \mathrm{kg}$ and 11.8 watts $/ \mathrm{kg}$ with an average of $6.4 \pm 1.8$ watts $/ \mathrm{kg}$. The extreme heart rates were 99 and 204 beats per minute with an average of $168.4 \pm 15.4$ beats per minute. Table 3 presents the percentiles of the developed power and the heart rate of the subjects by sex and age groups.

\subsection{3. $\mathrm{VO}_{2}$ Max on the Cycloergometer}

The extreme $\mathrm{VO}_{2}$ max of the subjects was $15.7 \mathrm{ml} / \mathrm{kg} / \mathrm{min}$ and $68.7 \mathrm{ml} / \mathrm{kg} / \mathrm{min}$ with the mean (standard deviation) of $33.4 \pm 9.3 \mathrm{ml} / \mathrm{kg} / \mathrm{min}$. It was $38.3 \pm 9.6$ $\mathrm{ml} / \mathrm{kg} / \mathrm{min}$ for men and $27.6 \pm 4.5 \mathrm{ml} / \mathrm{kg} / \mathrm{min}$ for women. Table 4 presents the percentiles of $\mathrm{VO}_{2}$ max by sex and age groups.

\subsubsection{Prediction of $\mathrm{VO}_{2}$ Max with the Cycloergometer}

The equation for predicting peak oxygen uptake by the six-minute walk test is as follows: $\mathrm{VO}_{2} \max (\mathrm{ml} / \mathrm{kg} / \mathrm{min})=[53.906+0.026 \mathrm{D}-0.395$ Weight -0.257 Age $9.204 \mathrm{Sex}] \pm 4.1 \mathrm{ml} / \mathrm{kg} / \mathrm{min}(\mathrm{R}=0.73)$. Table 5 shows the correlation data of $\mathrm{VO}_{2}$ max with the distance covered on the 6-minute walk test.

\section{Discussion}

\subsection{Six-Minute Walk Test Performance}

The average distance covered by subjects of our sample was $557.1 \pm 93.6 \mathrm{~m}$. This mean distance is greater than what was reported in the Arab population, by 
Table 2. Percentiles of distance traveled and heart rate of subjects on the 6-minute walk test according to age and gender.

\begin{tabular}{|c|c|c|c|c|c|c|c|c|}
\hline & & 5th & 10th & 25 th & 50 th & 75th & 90th & 95th \\
\hline \multicolumn{9}{|c|}{ Distance traveled } \\
\hline \multirow{5}{*}{ Male } & All ages & 424.7 & 459.0 & 526.0 & 600.0 & 682.9 & 711.0 & 730.1 \\
\hline & $<20$ & 568.6 & 580.4 & 601.5 & 644.5 & 685.0 & 713.5 & 738.8 \\
\hline & $20-30$ & 519.6 & 549.9 & 602.0 & 660.0 & 699.0 & 722.7 & 772.8 \\
\hline & $30-40$ & 414.2 & 445.1 & 485.5 & 542.5 & 602.5 & 655.0 & 735.5 \\
\hline & $40-50$ & 410.0 & 414.0 & 443.0 & 490.0 & 529.0 & 539.6 & 559.2 \\
\hline \multirow{5}{*}{ Female } & All ages & 405.0 & 411.8 & 460.0 & 513.8 & 558.5 & 610.0 & 660.0 \\
\hline & $<20$ & 499.0 & 525.4 & 540.0 & 558.0 & 596.0 & 649.8 & . \\
\hline & $20-30$ & 423.7 & 453.7 & 491.5 & 543.0 & 583.5 & 660.0 & 669.1 \\
\hline & $30-40$ & 393.8 & 407.5 & 425.5 & 485.0 & 517.5 & 556.5 & 600.0 \\
\hline & $40-50$ & 376.7 & 404.6 & 420.0 & 555.0 & 491.0 & 524.1 & 552.1 \\
\hline \multicolumn{9}{|c|}{ Cardiac frequency } \\
\hline \multirow{5}{*}{ Male } & All ages & 107.5 & 114.0 & 124.5 & 137.0 & 150.0 & 160.2 & 170.4 \\
\hline & $<20$ & 127.1 & 128.0 & 137.3 & 144.0 & 151.8 & 173.5 & 179.7 \\
\hline & $20-30$ & 100.8 & 108.0 & 126.0 & 140.0 & 152.5 & 161.5 & 173.3 \\
\hline & $30-40$ & 97.5 & 116.0 & 127.3 & 132.5 & 148.0 & 161.5 & 167.6 \\
\hline & $40-50$ & 108.8 & 112.0 & 120.0 & 124.0 & 133.0 & 154.0 & 175.6 \\
\hline \multirow{5}{*}{ Female } & All ages & 109.5 & 113.8 & 126.0 & 137.0 & 145.3 & 158.3 & 170.2 \\
\hline & $<20$ & 67.0 & 75.0 & 130.0 & 145.0 & 161.5 & 172.4 & . \\
\hline & $20-30$ & 107.8 & 116.4 & 130.5 & 139.5 & 149.8 & 170.7 & 182.5 \\
\hline & $30-40$ & 110.5 & 112.0 & 122.5 & 131.0 & 140.8 & 149.5 & 154.0 \\
\hline & $40-50$ & 111.5 & 115.0 & 122.0 & 133.0 & 141.0 & 149.2 & 154.5 \\
\hline
\end{tabular}

Table 3. Percentiles of power developed and heart rate of subjects in the step test according to age and gender.

\begin{tabular}{|c|c|c|c|c|c|c|c|c|}
\hline & & 5 th & 10th & 25 th & 50th & 75th & 90th & 95th \\
\hline \multicolumn{9}{|c|}{ Power developed } \\
\hline \multirow{5}{*}{ Male } & All ages & 4.97 & 5.49 & 6.17 & 6.86 & 8.23 & 9.60 & 9.60 \\
\hline & $<20$ & 6.86 & 6.86 & 7.55 & 8.23 & 8.92 & 9.60 & - \\
\hline & $20-30$ & 6.11 & 6.86 & 7.20 & 8.23 & 9.60 & 9.60 & 9.60 \\
\hline & $30-40$ & 4.22 & 5.07 & 5.49 & 6.86 & 6.86 & 8.23 & 8.23 \\
\hline & $40-50$ & 4.05 & 5.12 & 5.49 & 5.49 & 6.86 & 6.86 & 7.95 \\
\hline \multirow{5}{*}{ Female } & All ages & 2.74 & 4.12 & 4.12 & 5.49 & 6.75 & 6.86 & 7.99 \\
\hline & $<20$ & 4.12 & 4.12 & 5.49 & 6.12 & 6.86 & 7.07 & . \\
\hline & $20-30$ & 4.12 & 4.12 & 5.49 & 6.50 & 6.86 & 8.23 & 8.71 \\
\hline & $30-40$ & 2.94 & 4.12 & 4.12 & 4.12 & 5.49 & 5.49 & 5.49 \\
\hline & $40-50$ & 2.74 & 2.74 & 3.23 & 4.12 & 4.12 & 4.26 & 5.22 \\
\hline \multicolumn{9}{|c|}{ Cardiac frenquency } \\
\hline \multirow{5}{*}{ Male } & All ages & 155.0 & 156.0 & 163.0 & 173.0 & 181.5 & 193.0 & 196.0 \\
\hline & $<20$ & 167.0 & 167.4 & 173.5 & 180.0 & 194.0 & 201.2 & . \\
\hline & $20-30$ & 156.0 & 163.8 & 173.0 & 180.0 & 188.0 & 195.1 & 196.0 \\
\hline & $30-40$ & 153.9 & 157.2 & 160.5 & 166.0 & 171.0 & 177.4 & 187.3 \\
\hline & $40-50$ & 148.6 & 151.8 & 156.0 & 163.0 & 168.0 & 172.8 & 174.8 \\
\hline \multirow{5}{*}{ Female } & All ages & 141.2 & 146.0 & 155.0 & 159.0 & 173.0 & 188.8 & 192.0 \\
\hline & $<20$ & 148.0 & 156.0 & 168.0 & 177.0 & 185.0 & 193.2 & . \\
\hline & $20-30$ & 121.8 & 149.9 & 156.3 & 169.0 & 179.5 & 192.0 & 197.5 \\
\hline & $30-40$ & 138.6 & 143.8 & 154.0 & 158.0 & 160.0 & 164.7 & 168.4 \\
\hline & $40-50$ & 133.0 & 142.0 & 146.3 & 155.0 & 158.0 & 160.0 & 161.5 \\
\hline
\end{tabular}


Table 4. Percentiles of the subjects' $\mathrm{VO}_{2}$ max and heart rate during the cycloergometer test according to age and gender.

\begin{tabular}{|c|c|c|c|c|c|c|c|c|}
\hline & & 5 th & 10 th & 25 th & 50 th & 75th & 90th & 95th \\
\hline \multicolumn{9}{|c|}{$\mathrm{VO}_{2} \max$} \\
\hline \multirow{5}{*}{ Male } & All ages & 24.6 & 28.6 & 31.3 & 36.4 & 44.6 & 52.6 & 55.92 \\
\hline & $<20$ & 31.9 & 32.6 & 37.4 & 42.2 & 52.7 & 60.1 & 68.3 \\
\hline & $20-30$ & 29.8 & 33.0 & 35.2 & 40.2 & 48.6 & 53.9 & 56.7 \\
\hline & $30-40$ & 25.0 & 27.1 & 29.4 & 32.0 & 35.1 & 39.4 & 43.3 \\
\hline & $40-50$ & 22.3 & 23.6 & 26.4 & 29.8 & 32.9 & 34.3 & 38.6 \\
\hline \multirow{5}{*}{ Female } & All ages & 20.4 & 22.0 & 25.0 & 27.3 & 30.3 & 33.4 & 35.4 \\
\hline & $<20$ & 23.8 & 24.1 & 27.3 & 28.6 & 31.8 & 35.4 & - \\
\hline & $20-30$ & 23.1 & 24.6 & 25.7 & 28.5 & 31.4 & 35.0 & 37.4 \\
\hline & $30-40$ & 24.4 & 24.8 & 26.0 & 28.4 & 31.0 & 34.0 & 36.9 \\
\hline & $40-50$ & 16.2 & 17.8 & 20.8 & 22.8 & 25.3 & 28.1 & 31.5 \\
\hline \multicolumn{9}{|c|}{ Cardiac frequency } \\
\hline \multirow{5}{*}{ Male } & All ages & 166.0 & 169.6 & 174.0 & 180.0 & 186.0 & 194.0 & 197.1 \\
\hline & $<20$ & 166.4 & 173.1 & 176.3 & 183.5 & 191.8 & 193.8 & 197.8 \\
\hline & $20-30$ & 168.0 & 169.8 & 178.0 & 185.0 & 192.0 & 197.1 & 200.0 \\
\hline & $30-40$ & 155.6 & 168.2 & 174.0 & 178.0 & 181.0 & 182.6 & 184.7 \\
\hline & $40-50$ & 162.8 & 166.4 & 170.0 & 172.0 & 178.0 & 181.2 & 182.8 \\
\hline \multirow{5}{*}{ Female } & All ages & 166.0 & 170.0 & 172.0 & 178.0 & 183.0 & 188.0 & 189.0 \\
\hline & $<20$ & 176.0 & 177.8 & 184.0 & 186.5 & 188.3 & 192.2 & . \\
\hline & $20-30$ & 171.3 & 173.6 & 178.0 & 180.0 & 184.0 & 188.7 & 192.8 \\
\hline & $30-40$ & 168.5 & 170.0 & 174.3 & 177.0 & 178.8 & 182.0 & 182.8 \\
\hline & $40-50$ & 162.2 & 165.0 & 167.5 & 170.0 & 174.0 & 178.0 & 179.4 \\
\hline
\end{tabular}

Table 5. Correlation between $\mathrm{VO}_{2}$ max and traveled distance to 6-minute walk test.

\begin{tabular}{ccccc}
\hline & & \multicolumn{2}{c}{$\mathrm{VO}_{2} \max (\mathrm{ml} / \mathrm{kg} / \mathrm{min})$} & Statistical test \\
\cline { 3 - 5 } & & $<33$ & $>33$ & \\
\hline Distance traveled during the & $<557$ & 91 & 24 & $\mathrm{R}=0.65$ \\
6-minute walk test & $>557$ & 36 & 64 & $\mathrm{P}<0.00$ \\
\hline
\end{tabular}

Alameri et al. [18]. On the other hand, it is lower than what was found in the study of Chetta in 2001 and Prochaczek in 2007 [19] [20]. If we could evoke the question of age to explain the observed difference, it should be noted that our proportions remain lower than those of Chetta et al. in 2006, in a study population of identical age to ours (20 - 50 years) [19]. We can then simply make the assumption of the cultural question (sports practice, predominant mode of travel, etc.) to justify these noted differences. The average heart rate of subjects of our study was $136.7 \pm 19.0$ beats/minute, or $34.8 \%$ of the calculated theoretical maximum heart rate. This percentage shows that the test is submaximal. This average heart rate is higher than that found by some authors in the literature [20] [21] [22]. This difference may be related to reduced aerobic endurance in our cohort compared to these populations.

\subsection{Step Test Performance}

The average power of our subjects was $6.4 \pm 1.8$ watts $/ \mathrm{kg}$. This average exceeds 
those found in a study carried out by Nielens where the average power was 1.29 $\pm 0.39 \mathrm{~W} / \mathrm{kg}$ and $1.01 \pm 0.25 \mathrm{~W} / \mathrm{kg}$ respectively for men and women with chronic pain. In healthy subjects, it was $1.74 \pm 0.53 \mathrm{~W} / \mathrm{kg}$ and $1.08 \pm 0.40 \mathrm{~W} / \mathrm{kg}$ respectively for men and women [23]. This higher value in our study would be related in the fact that our subjects went to exhaustion while in the study of Nielens the test was stopped at a heart rate corresponding to $65 \%$ of the theoretical maximum heart rate calculated. The average heart rate was $168.4 \pm 15.4$ beats per minute, or $80.4 \%$ of the theoretical maximum heart rate. This percentage of FMT achieved shows that the test is under maximal despite the fact that subjects were allowed to go to exhaustion. This would be due to the discontinuous nature of the protocol. Indeed the two minutes of rest after each level allows a recovery and therefore a drop in heart rate.

\subsection{Performance of the Cycloergometer Test}

The mean maximum oxygen uptake $\left(\mathrm{VO}_{2}\right.$ max) of subjects of the study was 33.4 $\pm 9.3 \mathrm{ml} / \mathrm{kg} / \mathrm{min}$. Compared to other populations, the average $\mathrm{VO}_{2}$ max of Beninese is lower than that of Japanese, Americans, Norwegians and Canadians [24] [25] [26] [27]. But these results are clearly superior to those reported by Shete et al. in subjects who are not known athletes [28]. The average maximum heart rate of our cohort was $179.4 \pm 8.5$ beats per minute, or $89.5 \% \pm 7.1 \%$ of the calculated theoretical maximum heart rate. This percentage shows that this is a peak test. This average heart rate is similar to that obtained by Loe et al. in a Norwegian population [26].

\subsection{Correlation between the Distance Covered with a Six-Minute Walk and Maximum Oxygen Consumption}

The maximum distance traveled on the six-minute walk test was correlated with the maximum oxygen consumption estimated from the cycloergometer test $(\mathrm{r}=$ $0.65 ; \mathrm{p}<0.00)$. Burr et al. found a moderate correlation $(\mathrm{r}=0.54)$ in healthy subjects aged 20 to 59 years [29]. In populations suffering from respiratory pathologies, a correlation between distance travelled during the 6-minute walk test and $\mathrm{VO}_{2}$ max has also been found [30]. It is therefore possible to predict a subject's maximum oxygen uptake from the six-minute walk test. The $\mathrm{VO}_{2} \max$ prediction equation shows that the latter evolves inversely with respect to body weight, age and gender. The influence of sex on $\mathrm{VO}_{2}$ max is greater than that of others. Similar remarks were made by Burr et al. [29]. Also, Mänttäri et al. had noted that the predictors of the subject's performance on the six-minute walk test varied by gender [15]. From their analysis, it emerged that for men, the best predictors for $\mathrm{VO}_{2}$ max were walking distance, age, $\mathrm{BMI}$, heart rate at the end of $6 \mathrm{MWT}$ and height, and for women, walking distance, age and weight.

We can mention two main limitations to this study. This concerns the method of recruiting subjects and the taking into account of the heart rate as a parameter for assessing cardio-respiratory endurance. Indeed, a stratified cluster sampling would have been better. But, as we don't have specific motivating factors for the 
subjects, such a recruitment method is difficult in our socio-cultural context. About the heart rate, it is well known that various other parameters such as tests examination conditions or stress, could lead to disturbances.

\section{Conclusion}

This study enabled the establishment of normative values for the parameters of cardiovascular endurance in young Beninese adults. It emerges from this study that the standards found are different according to gender and age, as well as those of several other countries, justifying the importance of this work. It is therefore urgent to extend this study to other age groups of the population and to consider looking for other factors that may influence these standards.

\section{Conflicts of Interest}

The authors declare no conflicts of interest regarding the publication of this paper.

\section{References}

[1] Jeukendrup, A.E., Hesselink, K.C., Snyder, A.C., Kuipen, H. and Keiser, H.A. (1992) Physiological Changes in Male Competitive Cyclists after Two Weeks of Intensified Training. International Journal of Sports Medicine, 13, 534-541. https://doi.org/10.1055/s-2007-1021312

[2] Myers, J., McAuley, P., Lavie, C., Despres, J.P., Arena, R. and Kokkinos, P. (2015) Physical Activity and Cardiorespiratory Fitness as Major Markers of Cardiovascular Risk: Their Independent and Interwoven Importance to Health Status. Progress in Cardiovascular Diseases, 57, 306-315. https://doi.org/10.1016/j.pcad.2014.09.011

[3] Blair, S.N. (2009) Physical Inactivity: The Biggest Health Problem of the 21st Century. British Journal of Sports Medicine, 43, 1-2.

[4] Kokkinos, P. and Myers, J. (2010) Physical Activity: Clinical Outcomes and Applications. Circulation, 122, 1637-1648. https://doi.org/10.1161/CIRCULATIONAHA.110.948349

[5] Swift, D.L., Lavie, C.J. and Johannsen, N.M. (2013) Physical Activity, Cardio-Respiratory Fitness, and Exercise Training in Primary and Secondary Coronary Prevention. Circulation Journal, 77, 281-292. https://doi.org/10.1253/circj.CJ-13-0007

[6] Myers, J., Kaykha, A., George, S., Abella, J., Zaheer, N., Lear, S., et al. (2004) Fitness versus Physical Activity Patterns in Predicting Mortality in Men. The American Journal of Medicine, 117, 912-918. https://doi.org/10.1016/j.amjmed.2004.06.047

[7] Talbot, L.A., Morrell, C.H., Metter, E.J. and Fleg, J.L. (2002) Comparison of Cardiorespiratory Fitness versus Leisure Time Physical Activity as Predictors of Coronary Events in Men Aged 65 Years. American Journal of Cardiology, 89, 1187-1192. https://doi.org/10.1016/S0002-9149(02)02302-0

[8] Myers, J., Prakash, M., Froelicher, V., Do, D., Partington, S. and Atwood, J.E. (2002) Exercise Capacity and Mortality among Men Referred for Exercise Testing. The New England Journal of Medicine, 346, 793-801. https://doi.org/10.1056/NEJMoa011858

[9] Kodama, S., Saito, K. and Tanaka, S. (2009) Cardiorespiratory Fitness as a Quantitative Predictor of All-Cause Mortality and Cardiovascular Events in Healthy Men 
and Women: A Meta-Analysis. JAMA, 301, 2024-2035.

https://doi.org/10.1001/jama.2009.681

[10] Williams, P.T. (2001) Physical Fitness and Activity as Separate Heart Disease Risk Factors: A Meta-Analysis. Medicine \& Science in Sports \& Exercise, 33, 754-761. https://doi.org/10.1097/00005768-200105000-00012

[11] Balady, G.J., Larson, M.G., Vasan, R.S., Leip, E.P., O’Donnell, C.J. and Levy, D. (2004) Usefulness of Exercise Testing in the Prediction of Coronary Disease Risk among Asymptomatic Persons as a Function of the Framingham Risk Score. Circulation, 110, 1920-1925. https://doi.org/10.1161/01.CIR.0000143226.40607.71

[12] Mora, S., Redberg, R.F. and Cui, Y. (2003) Ability of Exercise Testing to Predict Cardiovascular and All-Cause Death in Asymptomatic Women: A 20-Year FollowUp of the Lipid Research Clinics Prevalence Study. JAMA, 290, 1600-1607. https://doi.org/10.1001/jama.290.12.1600

[13] Wen, C.P., Wai, J.P., Tsai, M.K., Yang, Y.C., Cheng, T.Y., Lee, M.C., et al. (2011) Minimum Amount of Physical Activity for Reduced Mortality and Extended Life Expectancy: A Prospective Cohort Study. The Lancet, 378, 1244-1253. https://doi.org/10.1016/S0140-6736(11)60749-6

[14] Kirkeberg, J.M., Dalleck, L.C., Kamphoff, C.S. and Pettitt, R.W. (2011) Validity of 3 Protocols for Verifying $\mathrm{VO}_{2}$ Max. International Journal of Sports Medicine, 32, $266-$ 270. https://doi.org/10.1055/s-0030-1269914

[15] Mänttäri, A., Suni, J., Sievänen, H., Husu, P., Vähä-Ypyä, H., Valkeinen, H., et al. (2018) Six-Minute Walk Test: A Tool for Predicting Maximal Aerobic Power $\left(\mathrm{VO}_{2}\right.$ Max) in Healthy Adults. Clinical Physiology and Functional Imaging, 38, 1038-1045. https://doi.org/10.1111/cpf.12525

[16] Vuori, I.M., Lavie, C.J. and Blair, S.N. (2013) Physical Activity Promotion in the Healthcare System. Mayo Clinic Proceedings, 88, 1446-1461. https://doi.org/10.1016/j.mayocp.2013.08.020

[17] Myers, J. (2008) On the Health Benefits and Economics of Physical Activity. Current Sports Medicine Reports, 7, 314-316. https://doi.org/10.1249/JSR.0b013e31818ee179

[18] Alameri, H., Al-Majed, S. and Al-Howaikan, A. (2009) Six Min Walk Test in Healthy Adult Arab Population. Respiratory Medecine, 103, 104-116. https://doi.org/10.1016/j.rmed.2009.01.012

[19] Chetta, A., Pisi, G., Zanini, A., Foresi, A., Grzincich, G.L., Aiello, M., et al. (2001) Six-Minute Walking Test in Cystic Fibrosis Adults with Mild to Moderate Lung Disease: Comparison to Healthy Subjects. Respiratory Medecine, 95, 986-991. https://doi.org/10.1053/rmed.2001.1194

[20] Prochaczek, F., Winiarska, H., Krzyzowska, M., Brandt, J.S., Swida, K.R., Szczurek, Z.W., et al. (2007) Six-Minute Walk Test on a Special Treadmill: Primary Results in Healthy Volunteers. Cardiology Journal, 14, 447-452.

[21] Chetta, A., Zanini, A., Pisi, G., Aiello, M., Tzani, P., Neri, M. and Olivieri, D. (2006) Reference Values for the 6-Min Walk Test in Healthy Subjects 20-50 Years Old. Respiratory Medecine, 100, 1573-1578. https://doi.org/10.1016/j.rmed.2006.01.001

[22] Soaresa, M.R. and Pereira, C.A. (2011) Six Minutes Walk Test Reference Values for Healthy Adults in Brazil. Jornal Brasileiro de Pneumologia, 37, 576-583.

[23] Nielens, H., Cornet, D. and Rigot, F. (2002) Maximal versus Submaximal Testing Protocols to Evaluate Fitness of Patients with Chronic Back Pain. Medicine \& Science in Sports \& Exercise, 34, 270. https://doi.org/10.1097/00005768-200205001-01515 
[24] Sanada, K., Kuchiki, T., Miyachi, M., McGrath, K. and Higuchi, M. (2007) Effects of Age on Ventilatory Threshold and Peak Oxygen Uptake Normalised for Regional Skeletal Muscle Mass in Japanese Men and Women Aged 20-80 Years. European Journal of Applied Physiology, 99, 475-483. https://doi.org/10.1007/s00421-006-0375-6

[25] Kaminsky, L.A., Ross, A. and Myers, J. (2015) Reference Standards for Cardiorespiratory Fitness Measured with Cardiopulmonary Exercise Testing: Data from the Fitness Registry and the Importance of Exercise National Database. Mayo Clinic Proceedings, 90, 1515-1523. https://doi.org/10.1016/j.mayocp.2015.07.026

[26] Loe, H., Steinshamn, S. and Wisløff, U. (2014) Cardio-Respiratory Reference Data in 4631 Healthy Men and Women 20-90 Years: The HUNT 3 Fitness Study. PLoS ONE, 9, e113884. https://doi.org/10.1371/journal.pone.0113884

[27] Shields, M., Tremblay, M.S., Laviolette, M., Craig, C.L., Janssen, I. and Connor, G.S. (2010) Fitness of Canadian Adults: Results from the 2007-2009 Canadian Health Measures Survey. Health Reports, 21, 21-35.

[28] Shete, A.N., Bute, S.S. and Deshmukh, P.R. (2014) A Study of $\mathrm{VO}_{2}$ Max and Body Fat Percentage in Female Athletes. Journal of Clinical and Diagnostic Research, 8 , BC01-BC03. https://doi.org/10.7860/JCDR/2014/10896.5329

[29] Burr, J.F. (2011) The 6-Minute Walk Test as a Predictor of Objectively Measured Aerobic Fitness in Healthy Working-Aged Adults. The Physician and Sport Medecine, 39, 133-139. https://doi.org/10.3810/psm.2011.05.1904

[30] Ross, R.M. (2010) The Six Minutes Walk Test Accurately Estimates Mean Peak Oxygen Uptake. BMC Pulmonary Medecine, 10, 31-39.

https://doi.org/10.1186/1471-2466-10-31 